\title{
Neurological Abnormalities Associated with Remote Occupational Elemental Mercury Exposure
}

\author{
James W. Albers, MD, PhD, ${ }^{\S}$ Lee R. Kallenbach, PhD, Lawrence J. Fine, MD, DrPh, ${ }_{\dagger} \dagger$ \\ Gary D. Langolf, PhD, $\ddagger$ Robert A. Wolfe, PhD, "Peter D. Donofrio, MD, ${ }^{*}$ Anthony G. Alessi, MD,* \\ Kathryn A. Stolp-Smith, MD, MS,§ Mark B. Bromberg, MD, PhD, ${ }^{*}$ and the Mercury Workers Study Group ${ }^{\#}$
}

We examined 502 subjects, 247 of whom had occupational elemental mercury exposures 20 to 35 years previously, to identify potential exposure-related neurological abnormalities. Few significant $(p<0.05)$ differences existed between exposed and unexposed subjects. However, multiple linear regression analysis demonstrated several significant correlations between declining neurological function and increasing exposure as determined by urine mercury measurements from the exposure interval. Subjects with urine mercury peak levels above $0.6 \mathrm{mg} / \mathrm{L}$ demonstrated significantly decreased strength, decreased coordination, increased tremor, decreased sensation, and increased prevalence of Babinski and snout reflexes when compared with the remaining subjects. Furthermore, subjects with clinical polyneuropathy had significantly higher peak levels than normal subjects $(0.85$ vs $0.61 \mathrm{mg} / \mathrm{L} ; p=0.04)$, but not increased exposure duration ( 20.1 vs 20.8 quarters; $p=0.34$ ), and $28 \%$ of subjects with peak levels above $0.85 \mathrm{mg} / \mathrm{L}$ had clinical evidence of polyneuropathy, compared with $10 \%$ of remaining subjects $(p=0.005)$. Although exposure was not age dependent, several neurological measures showed significant age-mercury interaction, suggesting that natural neuronal attrition may unmask prior exposure-related subclinical abnormalities.

Aibers JW, Kallenbach LR, Fine LJ, Langolf GD, Wolfe RA, Donofrio PD, Alessi AG, Stolp-Smith KA, Bromberg MB, Mercury Workers Study Group. Neurological abnormalities associated with remote occupational elemental mercury exposure. Ann Neurol 1988;24:651-659

Occupational exposure to elemental mercury has been associated with neurological abnormalities. In 1938 $\mathrm{Neal}$ and Jones examined 529 hatters exposed to mercury in fur-cutting industries and reported behavioral changes, abnormal tremor, and exaggerated reflexes [1]. Isolated exposures have been associated with polyneuropathy [2-5] and a syndrome resembling amyotrophic lateral sclerosis [6-8]. Most likely, specific clinical features depend upon the form, level, and duration of exposure [5, 9-12].

The effects of long-term trace metal exposure at levels below those associated with overt toxicity are unknown [13]. Evaluation is complicated because the onset of symptoms may be delayed for up to 30 years [14]. A relationship between cumulative mercury exposure and polyneuropathy has been established among dentists using mercury in the preparation of amalgam fillings [15], and evidence of polyneuropathy has been identified in asymptomatic chloralkali workers [16]. Because trace metal environmental and occupational exposures have been advanced to account for many conditions of unknown cause, it is important that information concerning potential health hazards from long-term or remote exposure be accumulated [13].

We used urine mercury measurement to estimate exposure in workers who were monitored as part of an industrial hygiene protocol to minimize mercury exposure. All mercury exposures occurred 20 to 35 years previously, allowing us to detect persistent neurological impairments or premature neurological deterioration in the absence of ongoing exposure.

\section{Methods}

Selection and Recruitment of Study Subjects

Elemental mercury was used in the studied plant between 1953 and 1963 in the production of lithium 6, a component
From the Departments of *Neurology, †Internal Medicine, $\ddagger$ Industrial and Operations Engineering, \$Physical Medicine and Rehabilitation, "Environmental and Industrial Health, and "Biostatiscics, The University of Michigan, Ann Arbor, MI.

\# Mercury Workers Study Group: Kirsten H. Alcser, PhD, Daniel T. Barry, MD, PhD, Trudy A. Borset, Kelley A. Brix, MD, MPH, Penny W. Chmura, RN, BSN, Kelly A. Cormier, Diana Echeverria, PhD, Andrew Miller, EMGT, Carhy J. Olszewski, EMGT, Carlos Sampaio, BS, Pamela S. Wilson, BS, Deborah Woodland, BA.
Received Jan 12, 1988, and in revised form Apr 19. Accepted for publication May 20, 1988.

Address correspondence to Dr Albers, University of Michigan Medical Center, 1500 East Medical Center Drive 1 C325/0032 UH, Ann Arbor, MI 48109-0032. 
of thermonuclear weapons. When production was discontinued, one of the two production facilities was dismantled during 1965 and 1966, and only low-level mercury exposure at that site was reported subsequently. $A$ cohort of all subjects exposed to elemental mercury who worked at least 4 months in the plant during the exposure interval was defined. Subjects were rank ordered using cumulative exposure (1953-1986) based on the sum of the average quarterly urinary mercury recordings $(\mathrm{mg} / \mathrm{L})$. Control subjects were selected from employees at the same plant during the same time interval who supposedly were never exposed to elemental mercury. Control subject selection used a frequency match to the mercury-exposed group for 5-year birth intervals, retirement status, and final job title. Eligible individuals included 2,136 exposed and 6,801 control subjects. Of those selected, $91 \%$ of the exposed and $93 \%$ of the control subjects were contacted. The response rate (percentage of examined vs contacted) was $85 \%$ and $78 \%$ for exposed and control subjects, respectively. In all, 247 exposed and 255 control subjects were examined. Potential selection bias was evaluated by contacting subjects who declined participation or cancelled their appointment ( 52 control, 28 mercury exposed) and comparing them with the participating subjects. No important differences were found; exposure levels were not significantly different, nor were health questionnaire responses. The evaluations received prior Human Subject Review Committee approval and informed consent was obtained from all subjects.

\section{Overall Study Design and Data Collection}

Subjects completed occupational and medical questionnaires with the assistance of a trained interviewer and underwent neurological examination. An arbitrarily selected subset of exposed $(n=195)$ and control $(n=191)$ subjects underwent electrodiagnostic examination. Individual evaluations required 3 to 4 hours; testing was conducted at the work site, with an equal number of exposed and control subjects scheduled per hour to minimize time-of-day effects (a method not known to examiners or subjects). Examiners had no indication of exposure levels, and different examiners performed the interview, urine mercury, neurological, and electrodiagnostic evaluations. Testing was conducted during 5 one-week intervals over 16 months.

\section{Questionnaire}

Specific questions were asked regarding the medical history including the present or prior use of medications. Lifestyle habits including smoking, caffeine consumption, and alcohol consumption were reviewed, as were exposures to known neurotoxins both at the plant and from other occupational or nonoccupational sources.

\section{Clinical Examination}

Examination was performed by one of two neurologists. A test-retest evaluation showed that the two neurologists did not differ significantly $(p<0.05)$ in their grading. Examination included a subjective classification of proximal and distal strength, upper extremity postural tremor, coordination (finger-to-nose and heel-to-knee), and muscle stretch reflexes (biceps brachii, brachioradialis, quadriceps, and
Achilles). The presence or absence of pathological reflexes (snout, jaw, and plantar) was recorded, and distal lower extremity pulses were evaluated.

Quantitative examinations included grip strength, touchpressure, two-point discrimination, vibratory, and pin-pain sensations. The quantitative measures were identical to those described previously [16], with the exception of vibratory sensation, which was determined using a $128-\mathrm{Hz}$ tuning fork. The intensity of vibration was measured with an acoustic vibrometer at the dominant index finger and great toe, and the descending threshold recorded as the average of the last two of four trials. Touch-pressure sensation was measured at the dorsum of the index finger and great toe with a pressure anesthesiometer (North Coast Medical, Inc, Campbell, CA). Subjects identified in which of two 3-second intervals the stimulus was delivered, and the descending threshold was determined in a forced-choice paradigm. Distal pin-pain sensation was determined subjectively and recorded as a ratio of the distal to proximal intensity. Grip strength was determined using a Jamar dynamometer (Asimow Engineering Company, Santa Monica, CA). Quantitative forearm postural tremor was measured as previously described $[17,18]$ using a Wilcoxon M408 accelerometer (Wilcoxon Research, Bethesda, MD). The root mean square and average absolute tremor amplitudes of acceleration tremor were recorded as the subject attempted to hold the input display steady (compensatory tracking task).

Additional examination was performed at the discretion of the neurologist to identify disorders that could complicate data analysis (familial tremor, diabetes mellitus, radiculopathy, etc). Clinical results were summarized as normal or abnormal. The presence of polyneuropathy or abnormal tremor, two established consequences of elemental mercury exposure, also was recorded. Other diagnoses were listed. A restricted group of exposed and control subjects was identified, after excluding subjects with medical or neurological conditions that could influence the neurological or electrodiagnostic examinations.

\section{Nerve Conduction Measurements}

Nerve conduction measurements were performed using standard surface stimulation and recording techniques [1921] and identical anatomical placement of electrodes for all subjects. Included were ulnar and tibial compound muscle action potential amplitude (distal stimulation); conduction velocity; distal latency; and $\mathrm{F}$ response latency (shortest latency of eight stimulations); as well as ulnar, median, and sural sensory nerve action potential amplitude, conduction velocity, and distal latency. Limb temperature was monitored and limbs were warmed if extremity temperature fell below $31^{\circ} \mathrm{C}$. Subjects with isolated abnormalities (e.g., carpal tunnel syndrome) were identified.

\section{Elemental Mercury Exposure Assessment}

Urine mercury levels were determined at least quarterly by dithizone colorimetric analysis, the conventional test at that time. Test-retest evaluations were unavailable; however, urine levels corresponded appropriately with more reliable average air sample levels. Multiple urine mercury indexes were used to characterize exposure $\{16,17\}$ based upon the 
Cumulative urine mercury $(\mathrm{mg} / \mathrm{L})$

Measure of integrated exposure calculated as the sum of the average urine level for each quarter in which measurements were taken. (The level of this variable was the basis for selection of the exposed group.)

Duration of exposure (number of quarters)

The number of quarters in which a subject had a detectable amount of elemental mercury in the urine.

Peak levels above $0.3 \mathrm{mg} / \mathrm{L}$ (number)

The number of quarters in which a subject had urine mercury measures greater than $0.3 \mathrm{mg} / \mathrm{L}$.

Peak levels above $0.6 \mathrm{mg} / \mathrm{L}$ (number)

The number of quarters in which a subject had urine mercury measures greater than $0.6 \mathrm{mg} / \mathrm{L}$.

Peak level (mg/L)

A subject's single highest urine mercury reading between January 1, 1953, and December 1966.

Average urine mercury $(\mathrm{mg} / \mathrm{L})$

The average urine mercury value for each subject between January 1, 1955, and December 31, 1956; if more than one reading was recorded in a given quarter, the average of all readings for the quarter was used.

plant urinalysis records, as summarized in Table 1 . The duration of exposure negatively correlated with all other measures, indicating that most of the exposure occurred at high levels over a short period of time. All three peak-level exposure measures correlated highly with each other as well as with the average mercury urine measures.

\section{Statistical Analysis}

The statistical analysis was designed to detect a threshold or a dose-response effect of mercury exposure on subject responses. Control and exposed subject responses were compared to detect an effect of any exposure at all. Subjects also were divided into two groups according to whether their peak exposure exceeded $0.6 \mathrm{mg} / \mathrm{L}$ and these two groups were compared to determine the effect of high-level exposure. Several measures of mercury exposure, including cumulative exposure, length of exposure, and peak exposure, were examined for dose-response relationships to responses.

Unadjusted comparisons of exposed with control groups were made using the Mann-Whitney $U$ test for ordinal and scaled responses and Fisher's exact test and $\chi^{2}$-analysis for categorical responses. Covariance and logistic models were used to test for differences in responses adjusted for age, height, and alcohol consumption. Simple and multiple linear and logistic regression models were used to detect doseresponse relationships between responses and mercury exposure levels. Simple regression models using mercury exposure level as the independent variable were used to evaluate unadjusted dose-response relationships, and multiple regression models were used for analyses adjusted for age, height, and alcohol consumption. Comparison of urine mercury levels for subjects with specific neurological abnormalities with those for subjects with normal examinations was made using the Mann-Whitney $U$ test.

Separate analyses were performed on the complete sample and on the restricted sample that excluded subjects with identified medical and neurological conditions presumably unrelated to mercury exposure. Multiple regression models based on the complete sample included a dummy variable to identify the excluded subgroup. Continuous and ordinal response measures were transformed to reduce skewness and the influence of exceptional values, when appropriate, in the covariance and linear regression models. There was no statistical evidence that the models were improved by using a logarithmic transformation of mercury exposure levels. A suspected age-mercury interaction was investigated in the regression models by including the product of a subject's age and mercury exposure level as an independent variable.

\section{Results \\ Comparisons Based upon Mercury Exposure Status}

Unadjusted comparison of the mercury-exposed and control subject groups demonstrated no significant ( $p$ $<0.05$ ) differences in age, height, weight, education, alcohol consumption, or reported abnormalities, other than a slightly larger proportion of subjects in the mercury-exposed group reporting history of malignancy ( $11.8 \%$ vs $6.7 \% ; p=0.05$ ). In the total sample, the clinical and quantitative examination measures demonstrated only one significant group difference. There was significantly increased quantitative tremor in the exposed group compared with the control group (root mean square: 94 vs $80 \mathrm{~mm} / \mathrm{sec}^{2}, p=0.04$; and average amplitude: 74 vs $63 \mathrm{~mm} / \mathrm{sec}^{2}, p=0.03$ ). These differences were not significant in the restricted group comparison, although joint position sensation (foot) demonstrated significantly more errors in the exposed than in control subjects in this subgroup $(0.20$ vs 0.08 errors $/ 10$ trials; $p=0.05$ ). This finding was complicated by the existence of significant interaction with several baseline variables. Overall, the few significant differences were very small, although mean performance consistently was worse in the exposed than in control group for most measures.

The electrodiagnostic evaluation results demonstrated no statistically significant group differences using the Mann-Whitney $\mathrm{U}$ test and only one significant difference (median sensory amplitude) in the covariance analysis, after adjusting for age, height, weight, finger size, and reported lead exposure. This difference was not significant in the restricted group analysis. 


\section{Dose-Response Analysis}

Multiple linear regression analysis of cumulative and peak urine mercury with neurological examination measures demonstrated consistently positive correlations between declining neurological performance and increasing mercury exposure. Significant regression coefficients were identified for measures of strength (proximal and distal), coordination (arms), tremor (postural and quantitative), and sensation (joint position/ foot, two-point discrimination/hand, touch-pressure/ foot, and vibration/foot). Good agreement existed between the two urine mercury history variables, although a greater number of significant coefficients existed using the peak urine mercury measure. These findings suggest a weak but significant dose-response relationship between abnormal neurological function and increasing mercury exposure. Results were similar for the total and restricted group comparisons.

Multiple regression analysis of cumulative urine mercury and electrodiagnostic results identified no significant dose-response relationships, although the total number of sensory and motor nerve abnormalities approached statistical significance $(p=0.07$ and 0.06 , respectively). Statistically significant regression coefficients were identified for the median sensory distal latency and the total number of motor nerve abnormalities using the peak urine mercury variable.

Several regression lines were substantially influenced by a small number of subjects. Specifically, doseresponse relationships between measures of coordination, postural tremor, joint position sensation, and vibration sensation, and the mercury measures were no longer significant after no more than 3 subjects were removed. Similar influence by a small number of subjects was not demonstrated for the measures of strength, two-point discrimination, or touch-pressure sensation.

\section{Selective Evaluation of Subjects}

\section{with High Peak Mercury Exposure}

Because of the suggested dose-response relationships, subjects were divided into two groups: subjects with one or more urine mercury peaks above $0.6 \mathrm{mg} / \mathrm{L}(\mathrm{n}$ $=112$ ) and those without a history of such peaks ( $\mathrm{n}=$ 390). This exposure level was chosen because of its conventional use as a measure of substantial exposure [17]. For most measures, mean neurological performance was worse and the presence of neurological abnormalities more common in the higher mercury exposure group (Table 2). Significant $(p<0.05)$ differences existed in tests of strength (proximal and distal), coordination (legs), postural tremor, quantitative tremor, two-point discrimination (hand), touchpressure sensation (foot), Babinski reflex, and snout reflex. A significantly lower percentage of subjects in the high-exposure group had a normal neurological examination $(42.6 \%$ vs $54.4 \% ; p=0.05)$.

To examine further a possible relationship berween clinical polyneuropathy and mercury exposure, exposed subjects were separated into four groups based upon urine mercury peak values. In the highest exposure group (peak above $0.85 \mathrm{mg} / \mathrm{L}$ ), $28 \%$ of subjects had clinical evidence of polyneuropathy (Table 3). By comparison, only $10 \%$ of remaining subjects had polyneuropathy $\left(\chi^{2} ; p=0.005\right)$. Multiple logistic regression analysis suggested that subjects with a urine mercury peak above $0.85 \mathrm{mg} / \mathrm{L}$ had approximately a twofold to threefold increased risk of having a clinically detectable polyneuropathy.

Electrodiagnostic examination results also were compared between subjects with one or more urine mercury peaks above $0.6 \mathrm{mg} / \mathrm{L}(\mathrm{n}=95)$ and subjects without such peaks $(n=291)$. The only significant difference was a slightly prolonged median sensory distal latency in the higher-compared with the lowerexposure group. The mean difference of $0.1 \mathrm{msec}$ was of questionable clinical significance. Further subdivision of exposed subjects into groups with two or more urine mercury peaks above $0.6 \mathrm{mg} / \mathrm{L}(\mathrm{n}=39)$ and those without such peaks $(\mathrm{n}=347$ ) demonstrated a significantly increased number of sensory and motor nerve abnormalities in the higher-compared with the lower-exposure group $(p=0.04$ and $p=0.005$, respectively). Using three or more urine mercury peaks above $0.6 \mathrm{mg} / \mathrm{L}(\mathrm{n}=15)$, the number of motor nerve abnormalities again was significantly higher in the higher-exposure group ( $p=0.001$ ), although the number of sensory nerve abnormalities was no longer significantly different between groups. Similar results were obtained using the restricted group.

\section{Urine Mercury Comparison For Abnormal and Normal Exposed Subjects}

If abnormalities were related to the magnitude of prior mercury exposure and present only in subjects having the highest exposure, comparison of mercury indexes for "abnormal" and "normal" exposed subjects might be more sensitive than group comparisons [16], because subjects with low-exposure levels would dilute the exposed group. Because the dose-response studies suggested a weak but significant relationship between tremor and several tests of sensation, mercury-exposed subjects with abnormal tremor or polyneuropathy were compared with exposed subjects having neither abnormal tremor nor polyneuropathy.

Exposed subjects with abnormal tremor (equal to or greater than "trace") had significantly higher urine mercury peak levels than exposed subjects without evidence of tremor $(0.72$ vs $0.61 \mathrm{mg} / \mathrm{L} ; p=0.03)$. None of the other urine mercury measures was significantly different. Stratifying the subjects into groups 


\begin{tabular}{|c|c|c|c|}
\hline \multirow[b]{2}{*}{ Response/Measure } & \multicolumn{3}{|c|}{ Utine Mercury Peak Above $0.6 \mathrm{mg} / \mathrm{L}$} \\
\hline & $\begin{array}{l}\text { Yes } \\
(\mathrm{n}=112)\end{array}$ & $\begin{array}{l}\text { No } \\
(\mathbf{n}=390)\end{array}$ & $p$ Value $^{\mathrm{b}}$ \\
\hline \multicolumn{4}{|l|}{ Strength } \\
\hline Proximal strength $(\%)^{\mathrm{c}}$ & 3.1 & 0.1 & 0.02 \\
\hline Distal strength (\%) & 6.0 & 1.8 & 0.01 \\
\hline Grip strength $(\mathrm{kg})$ & $43.4(0.74)$ & $43.5(0.40)$ & 0.94 \\
\hline \multicolumn{4}{|l|}{ Tremor } \\
\hline Coordination-arms $(\%)$ & 23.0 & 15.9 & 0.07 \\
\hline Coordination-legs $(\%)$ & 5.3 & 1.9 & 0.04 \\
\hline Postural tremor $(\%)$ & 35.2 & 25.6 & 0.05 \\
\hline Acceleration tremor (root mean square, $\mathrm{mm} / \mathrm{sec}^{2}$ ) & $94(4)$ & $80(2)$ & 0.002 \\
\hline Acceleration tremor (average amplitude, $\mathrm{mm} / \mathrm{sec}^{2}$ ) & $74(3)$ & $63(2)$ & 0.001 \\
\hline \multicolumn{4}{|l|}{ Sensation } \\
\hline \multicolumn{4}{|l|}{ Joint position (no. errors/10 trials) } \\
\hline Hand & $0.01(0.01)$ & $0.02(0.02)$ & 0.41 \\
\hline Foot & $0.40(0.09)$ & $0.20(0.05)$ & $0.09^{f}$ \\
\hline \multicolumn{4}{|l|}{ Pin-pain, distal/proximal (ratio $\times 100)$} \\
\hline Hand & $183.4(10.4)$ & $182.6(5.6)$ & 0.95 \\
\hline Foot & $127.8(7.6)$ & $125.9(4.0)$ & 0.82 \\
\hline \multicolumn{4}{|l|}{ Two-point discrimination (mm) } \\
\hline Hand & $4.9(0.16)$ & $4.5(0.09)$ & 0.04 \\
\hline Foot & $33.9(1.4)$ & $33.2(0.7)$ & 0.65 \\
\hline \multicolumn{4}{|l|}{ Touch-pressure (log mg) } \\
\hline Hand & $3.6(0.04)$ & $3.6(0.02)$ & 0.33 \\
\hline Foot & $4.0(0.04)$ & $3.8(0.02)$ & $0.01^{f}$ \\
\hline \multicolumn{4}{|l|}{ Vibration (vibration units) } \\
\hline Hand & $8.6(0.26)$ & $8.3(0.14)$ & 0.30 \\
\hline Foot & $16.3(0.42)$ & $15.6(0.22)$ & 0.14 \\
\hline \multicolumn{4}{|l|}{ Reflexes } \\
\hline \multicolumn{4}{|l|}{ Muscle stretch reflexes ${ }^{e}$} \\
\hline Biceps & $2.0(0.08)$ & $2.0(0.04)$ & 0.85 \\
\hline Brachioradialis & $1.8(0.08)$ & $1.9(0.04)$ & 0.47 \\
\hline Quadriceps & $2.3(0.08)$ & $2.2(0.04)$ & 0.69 \\
\hline Achilles & $1.6(0.08)$ & $1.7(0.05)$ & 0.20 \\
\hline \multicolumn{4}{|l|}{ Pathological reflexes $(\%)$} \\
\hline Babinski & 5.7 & 1.9 & 0.04 \\
\hline Jaw & 9.1 & 5.8 & 0.19 \\
\hline Snout & 49.5 & 37.8 & 0.03 \\
\hline
\end{tabular}

${ }^{2}$ Values other than percentages reflect the adjusted mean and, in parentheses, standard error.

${ }^{\text {b}}$ Covariance analysis was used for parametric data: test for difference in adjusted means, adjusting for age (years) and lead exposure (no, yes). Logistic regression analysis was used for percents to adjust for age (years) and lead exposure (no, yes).

'Percent of subjects with abnormal condition for all percentile scores.

¿Vibration units proportional to log-scaled displacement.

${ }^{\mathrm{e}} 0$ to $4+: 0=$ absent; $2+=$ normal.

fSignificant interaction $(p<0.01)$, for differences in coefficients of adjusters.

Table 3. Neurological Examination Summary for Polyneuropatby: Comparison Between Mercury-Exposed Subjects ( $n=247)$ with Different Peak Urine Mercury History Levels

\begin{tabular}{lllll}
\hline & & \multicolumn{2}{c}{ Urinary Mercury Peak Levels $(\mathrm{mg} / \mathrm{L})$} \\
\cline { 2 - 5 } Response & $\begin{array}{l}<0.45 \\
(\mathrm{n}=86)\end{array}$ & $\begin{array}{l}0.45-0.69 \\
(\mathrm{n}=77)\end{array}$ & $\begin{array}{l}0.70-0.85 \\
(\mathrm{n}=33)\end{array}$ & $\begin{array}{l}>0.85 \\
(\mathrm{n}=51)\end{array}$ \\
\hline Normal $(\%)^{\mathrm{a}}$ & 73.3 & 75.3 & 72.7 & 56.9 \\
Equivocal polyneuropathy $(\%)^{\text {Polyneuropathy }(\%)}$ & 14.0 & 16.9 & 18.2 & 15.7 \\
\hline
\end{tabular}

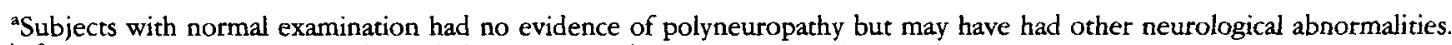

${ }^{b} \chi^{2}$ analysis; subjects with peak level above $0.85 \mathrm{mg} / \mathrm{L}$ vs remaining subjects, $p<0.01$. 
Table 4. Comparison of Urine Mercury History Variables for Subjects with Clinical or Clinical and Electrodiagnostic Evidence of Polyneuropatby versus Subjects with Normal Clinical and Electrodiagnostic Evaluation ${ }^{\mathrm{a}}$

\begin{tabular}{|c|c|c|c|c|c|}
\hline Urine Mercury History Variables & $\begin{array}{l}\text { Normal } \\
(n=174)\end{array}$ & $\begin{array}{l}\text { Clinical } \\
\text { Polyneuropathy } \\
(\mathrm{n}=34)\end{array}$ & $p$ Value $^{\mathrm{b}}$ & $\begin{array}{l}\text { Clinical and EDX } \\
\text { Polyneuropathy } \\
(n=16)\end{array}$ & $p$ Vahne \\
\hline $\begin{array}{l}\text { Cumulative urine mercury level (sum } \\
\text { of average quarterly values, } \mathrm{mg} / \mathrm{L} \text { ) }\end{array}$ & $3.48(1.10)$ & $3.89(1.57)$ & 0.51 & $4.34(1.71)$ & 0.08 \\
\hline Duration of exposure (no. quarters) & $20.8(9.1)$ & $20.1(9.0)$ & 0.34 & $20.5(9.4)$ & 0.65 \\
\hline Peak levels $>0.3 \mathrm{mg} / \mathrm{L}$ (no.) & $3.3(2.4)$ & $4.2(2.8)$ & 0.17 & $5.6(3.1)$ & 0.006 \\
\hline Peak levels $>0.6 \mathrm{mg} / \mathrm{L}$ (no.) & $0.7(1.0)$ & $1.1(1.4)$ & 0.13 & $1.1(1.3)$ & 0.32 \\
\hline $\begin{array}{l}\text { Peak level (highest level in entire his- } \\
\text { tory, } \mathrm{mg} / \mathrm{L} \text { ) }\end{array}$ & $0.61(0.29)$ & $0.85(0.64)$ & 0.04 & $0.84(0.66)$ & 0.20 \\
\hline $\begin{array}{l}\text { Average urine mercury, } 1955-1956 \\
(\mathrm{mg} / \mathrm{L})\end{array}$ & $0.26(0.13)$ & $0.30(0.15)$ & 0.12 & $0.33(0.14)$ & 0.14 \\
\hline
\end{tabular}

${ }^{a}$ Values represent the mean and, in parentheses, the standard deviation.

${ }^{b}$ Mann-Whitney U test.

EDX = electrodiagnostic.

Table 5. Percentage of Subjects Excluded from the Mercury Exposed and Control Groups

Because of Neurological Disorders Presumed Attributable to Causes Other than Mercury Exposure

\begin{tabular}{|c|c|c|c|}
\hline Cause of Abnormality & $\begin{array}{l}\text { Mercury Exposed } \\
\text { (\%-positive) } \\
(\mathrm{n}=247)\end{array}$ & $\begin{array}{l}\text { Control } \\
\text { (\%-positive) } \\
(\mathrm{n}=255)\end{array}$ & $p$ Value $^{a}$ \\
\hline Neoplasm with or without chemotherapy or radiation therapy & 2.0 & 1.2 & 0.36 \\
\hline Trauma & 0.8 & 1.6 & 0.35 \\
\hline Toxic or medication exposure & 2.8 & 1.6 & 0.27 \\
\hline Structural & 3.2 & 2.7 & 0.49 \\
\hline Vascular & 1.2 & 2.4 & 0.26 \\
\hline Psychiatric & 0.8 & 0.4 & 0.50 \\
\hline Inflammatory & 0.8 & 0.4 & 0.50 \\
\hline Connective tissue disorder & 0.8 & 0.4 & 0.50 \\
\hline Metabolic & 9.3 & 6.7 & 0.15 \\
\hline Nutritional & 0.4 & 0.8 & 0.50 \\
\hline Unknown & 7.3 & 3.1 & 0.03 \\
\hline
\end{tabular}

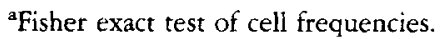

with increasing levels of tremor did not demonstrate any additional findings.

Exposed subjects with polyneuropathy had significantly higher urine mercury peak levels than exposed subjects with normal neurological examinations $(0.85$ vs $0.61 \mathrm{mg} / \mathrm{L} ; p=0.04)$, and all of the remaining urine mercury history variables except duration of exposure were greater for subjects with polyneuropathy than those without polyneuropathy (Table 4). Subjects having both clinical and electrodiagnostic evidence of polyneuropathy had a significantly increased number of urine mercury peaks exceeding $0.3 \mathrm{mg} / \mathrm{L}$ compared with exposed subjects having normal examinations ( 5.6 vs $3.3 \mathrm{mg} / \mathrm{L} ; p=0.006$ ). Four of the remaining five mercury history variables demonstrated higher mercury exposure in the polyneuropathy group, but not significantly so. The only index not higher was the duration of exposure.

\section{Evaluation of Excluded Subjects}

The restricted subject group was developed to identify subjects with abnormalities presumably unrelated to mercury exposure that could influence test results. The 108 excluded subjects were distributed evenly between the mercury-exposed (54) and control groups (54). Subdivision of the subjects into categories based upon the presumed cause of the abnormality is shown in Table 5. The only category with a significantly uneven distribution was the one designated "unknown" cause, where there was a greater percentage of excluded subjects in the exposed group.

The mercury-exposed subjects with neurological ab- 


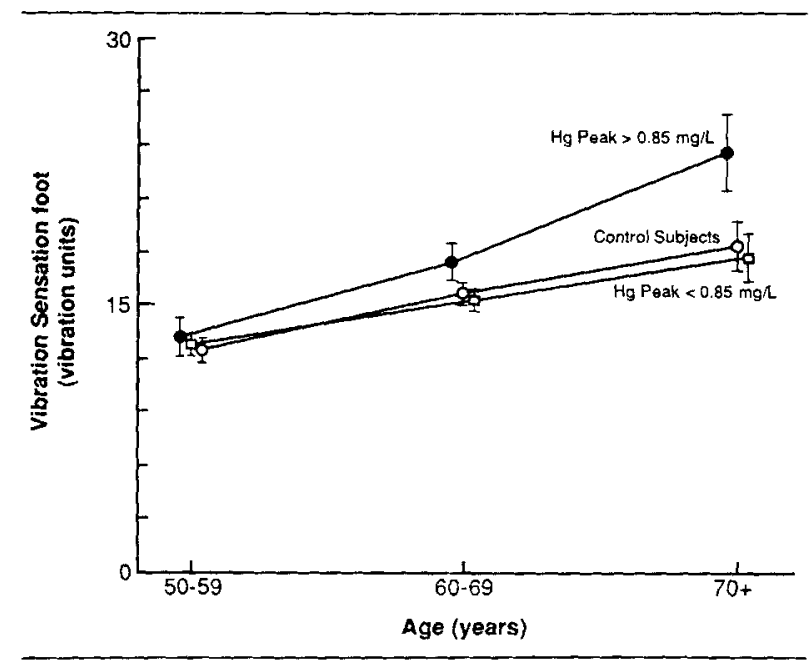

Demonstration of age-mercury interaction. Vibration sensation (foot) as a function of age for control subjects (open circles) and subjects with two levels of mercury exposure, peak $<0.85 \mathrm{mg} / \mathrm{L}$ (open squares) and peak $>0.85 \mathrm{mg} / \mathrm{L}$ (closed circles). Vibration units are proportional to log-scaled displacement. Standard error is represented by vertical bars.

normalities of unknown cause had findings consistent with myelopathy (undefined level) in 11 of 18 subjects. Six other subjects had abnormal tremor plus additional findings suggestive of parkinsonism or a family history of similar tremor. The remaining subject had evidence of dementia.

The 8 control subjects with neurological abnormalities of unknown cause included 4 subjects with findings suggestive of myelopathy, 3 subjects with abnormal tremor plus evidence of parkinsonism or a family history of tremor, and 1 subject with idiopathic postural hypotension. Although the proportion of subjects with mild myelopathy was higher in mercuryexposed than in control subjects (11 of 247 vs 4 of 255 , respectively), the difference was of marginal statistical significance $\left(4.4 \%\right.$ versus $1.6 \% ; \chi^{2}=3.59, p$ $=0.06$ ). This unexpected finding is based on a small number of subjects, and comparison of urine mercury history variables for the 11 exposed subjects with myelopathy with those for exposed subjects with a normal clinical examination demonstrated no significant differences.

\section{Age and Exposure Interaction}

Most subjects demonstrated poorer performance with increasing age. For several measures, subjects with prior mercury exposure showed more pronounced age-related trends toward deteriorating performance than did control subjects. Significant age-cumulative mercury interaction was demonstrated for proximal and distal strength, quantitative tremor, touch-pressure sensation (foot), and vibration sensation (foot). In addition, two-point discrimination and number of motor nerve abnormalities had a significant age-peak mercury interaction. Averaged vibration sensation as a function of age by decade is shown for control subjects and subjects with two levels of mercury exposure (peak $<0.85 \mathrm{mg} / \mathrm{L}$, peak $>0.85 \mathrm{mg} / \mathrm{L}$ ) in the figure. This Figure is representative of the other outcome measures showing a significant age-mercury exposure interaction. In the Figure, subjects 70 years of age and older demonstrated the most significant differences between high- and low-exposure or control subjects. Mercury exposure was not significantly different between the younger and the older subjects.

\section{Discussion}

Mercury-exposed and control group comparisons demonstrated few significant differences. Nevertheless, the finding of increased tremor in exposed compared with control subjects was similar to previous results [17]. Only a few other measures approached statistical significance, although all differences favored poorer performance in the exposed group.

Dose-response analyses showed significant relationships between peak and cumulative urine mercury measures and several neurological measures. These two urine mercury measures were chosen because previous experience suggested that they best reflected mercury exposure [16]. All significant correlation coefficients were small $(r=0.10-0.16)$ and much smaller than reported previously $(r=0.19-0.39)$ for subjects with ongoing mercury exposure [16]. Electrodiagnostic measures demonstrated only a few significant relationships with peak urine mercury measures, and all correlation coefficients were small $(r=$ $0.10-0.11$ ). Although the correlation coefficients increase with increasing exposure [22], our current findings suggest that the interval between exposure and evaluation also is important.

The significant correlation between the number of motor nerve abnormalities and the peak urine mercury measure was surprising because the number of sensory nerve abnormalities did not demonstrate a statistically significant similar trend. This relationship is different from that reported previously $[16,22]$ and from most accounts of mercury polyneuropathy $[9,15,16,23$, $24]$, although isolated reports of clinical motor involvement with minimal or no sensory abnormalities exist [2, 6-8]. Lead polyneuropathy may have promiment motor nerve predilection, with minimal or no sensory symptoms or signs $[5,25]$. However, lead was not found to be a significant covariate for electrodiagnostic abnormalities. The lead measure was based on urinary lead levels; less than $10 \%$ of exposed subjects were employed in jobs with lead exposure. We did not identify subjects with pure motor involvement clinically suggestive of amyotrophic lateral sclerosis.

Direct comparisons of exposed and control groups 
could be insufficient to associate prior mercury exposure with a neurological impairment if previously mild abnormalities resolved over time, diluting the exposed group with subjects no longer demonstrating abnormalities. Subjects with high mercury exposure were therefore compared with those with low exposure, and urine mercury history variables compared between subjects with specific neurological findings and subjects with normal examinations. Both comparisons supported an association between prior mercury exposure and deteriorating neurological performance.

Subjects with one or more urine mercury peaks above $0.6 \mathrm{mg} / \mathrm{L}$, a conventional measure of substantial exposure $[17,26]$, demonstrated poorer performance in several neurological measures compared with subjects without such peaks. One central or peripheral nervous system disorder cannot explain the findings. Although the sensory abnormalities are consistent with either central or peripheral nervous system involvement, the increased prevalence of Babinski and snout reflexes in the higher-exposure group cannot be attributed to a peripheral lesion. This increased prevalence of Babinski and snout reflexes should be interpreted cautiously because it has not been associated with this level of mercury exposure in other studies. The high (38\%) prevalence of snout reflex in the low-exposure group is similar to the $30 \%$ frequency reported for normal aged subjects [27]. We have no additional evidence to suggest that mercury exposure causes bilateral supranuclear lesions or diffuse cerebral degeneration. Specifically, cognitive effects were not identified (to be reported separately). Nevertheless, subjects with higher exposure were significantly less likely to have a normal examination than other subjects; the abnormalities were consistent with previous reports of widespread neurological involvement $[9,10,14,28$, 29].

The further subdivision of exposed subjects into groups based upon urine mercury peaks demonstrated a significantly greater percentage of subjects in the highest-exposure group with clinical evidence of polyneuropathy. The relative risk of polyneuropathy was increased approximately twofold to threefold compared with the lower-exposure groups. These findings, together with the electrodiagnostic evaluations, were characteristic of a peripheral sensorimotor axonal polyneuropathy and consistent with the purported association between elemental mercury exposure and polyneuropathy $[4,5,9,12,15,16,22,29]$.

Comparison of the mercury indexes for exposed subjects with specific neurological abnormalities with those for exposed subjects with normal examinations was felt to be the most sensitive way of determining whether the impairments could be attributed to mercury exposure [16]. For subjects with abnormal tremor, the finding of a significantly increased urine mercury peak level was similar to a finding in an earlier report involving chloralkali workers [17], although the magnitude of tremor was less. There, urine mercury peaks in excess of $0.5 \mathrm{mg} / \mathrm{L}$ were most important in predicting increased tremor. Our current results suggest that the abnormality is a long-lasting or a late effect following remote exposure. This was surprising because we had previously demonstrated that tremor decreased after subjects were removed from ongoing mercury exposure [17].

Subjects with polyneuropathy also had evidence of significantly higher mercury exposure than subjects with normal examinations. Significant differences existed for urine mercury peak levels and number of peak levels exceeding $0.3 \mathrm{mg} / \mathrm{L}$. The duration of exposure demonstrated little relationship to the presence or absence of polyneuropathy. Although subjects with polyneuropathy tended to be older than subjects without polyneuropathy, the urine mercury measures did not demonstrate a similar age dependence. These findings suggest that higher levels of mercury exposures are associated with more evidence of polyneuropathy long after exposure than chronic low-level exposures.

It is not surprising that remote mercury exposure that ceased 20 or more years before did not have a dramatic effect. Exposure-related neurological dysfunction is often reversible, and only rarely is the toxic exposure so massive or the neuronal target so vulnerable that irreversible neuronal changes ensue $[30,31]$. Nevertheless, 18 exposed subjects had clinical polyneuropathy for which no cause other than mercury exposure was apparent. Abnormalities were most apparent in the lower limbs, and findings of diminished vibratory sensation and hypoactive Achilles reflexes were consistent with large-fiber involvement. Comparison with 17 control subjects with diabetes mellitus demonstrated only one significant difference, namely increased postural tremor in exposed subjects, indicating that the magnitude of peripheral involvement was comparable with that found in a random selection of diabetic subjects.

The equal number of excluded subjects from the exposed and control groups suggests that a previously unidentified mercury-associated abnormality was not being overlooked. Nevertheless, there was a marginally significant $(p=0.06$ ) uneven distribution of nonspecific myelopathy among exposed subjects. This potential association between myelopathy and mercury exposure was not supported by urine mercury comparisons; no significant differences were demonstrated between the subjects with myelopathy and the subjects with normal examinations.

The observation that aging may unmask prior subclinical damage is important $[18,32]$. Our finding that many measures demonstrating significant differences 
between exposed and unexposed subjects were age dependent is consistent with suggested models of remote neuronal damage that becomes unmasked as a consequence of age-related neuronal attrition [32]. Disorders consistent with this hypothesis include late progression of prior poliomyelitis, trauma related to boxing with subsequent encephalopathy and parkinsonism, remote radiation-associated plexopathy or myelopathy, and the amyotrophic lateral sclerosisdementia complex of Guam [32]. The latter syndrome has recently been linked to ingestion of a neurotoxic amino acid component of the cycad seed, a traditional food source in Guam [33]; the effects sometimes are delayed up to 3 decades or more following exposure. Such delayed involvement presumably depends upon a threshold effect, whereby neuronal loss below a certain level results in neurological impairment and subthreshold damage results in no identifiable impairment. Over time, age-related neuronal attrition results in development of neurological findings. In such a model, the severity of the initial damage directly influences the latent interval between exposure and appearance of neurological impairment. This model has obvious therapeutic and causative implications, and our data provide support for a delayed, remote elemental mercury effect upon the nervous system.

Supported in part by Martin Marietta Energy Systems Contract \#SC86Y-22010C, "A Health Evaluation of Y-12 Workers Formerly Exposed to Mercury."

The time, effort, and support of many individuals within the management and the unions at Martin Marietta Energy Systems, Inc, enabled this study to be successfully completed. We specifically would like to acknowledge the support of Robert Kyle, William Akers, Edward Bailey, Dr Shirley Frye, Dr Donna Craigle, Phillip Wallace, Julia McClanahan, and Delores Payne.

\section{References}

1. Neal PA, Jones RR. Chronic mercurialism in the hatter's furcutting industry. JAMA 1938;110:337-343

2. Ross AT. Mercuric polyneuropathy with albumino-cytologic dissociation and eosinophilia. JAMA 1964;188:830-831

3. Iyer K. Goodgold J, Eberstein A, Berg P. Mercury poisoning in a dentist. Arch Neurol 1976;33:788-790

4. Markowitz L, Schaumburg HH. Successful treatment of inorganic mercury neurotoxicity with $\mathrm{N}$-acetyl-penicillamine despite an adverse reaction. Neurology 1980;30:1000-1001

5. Windebank AJ, McCall JT, Dyck PJ. Metal neuropathy. In: Dyck PJ, Thomas PK, Lambert EH, Bunge R, eds. Peripheral neuropathy, vol II. 2nd ed. Philadelphia: Saunders, 1984:21332161

6. Vroom FQ, Greer M. Mercury vapor intoxication. Brain 1972;95:305-318

7. Barber TE. Inorganic mercury intoxication reminiscent of amyotrophic lateral sclerosis. J Occup Med 1978;20:667-669

8. Adams CR, Ziegler DK, Lynn JT. Mercury intoxication simulating amyotrophic lateral sclerosis. JAMA 1983;250:642-643

9. Feldman RG. Neurological manifestations of mercury intoxication. Acta Neurol Scand 1982;66(no. 92, suppl):201-209
10. McNeil NI, Issler HC, Olver RE, Wrong OM. Domestic metallic mercury poisoning. Lancet 1984;8371:269-271

11. Taylor JR. Neurotoxicity of certain environmental substances. Clin Lab Med 1984;3:489-497

12. Windebank AJ. Specific inhibition of myelination by lead in vitro; comparison with arsenic, thallium, and mercury. Exp Neurol 1986;94:203-212

13. Ulmer DD. Trace elements (medical intelligence; current concepts). N Engl J Med 1977;297:318-321

14. Chang LW. Mercury. In: Spencer PS, Schaumburg HH, eds. Experimental and clinical neurotoxicology. Baltimore: Williams \& Wilkins, 1980:508-\$26

15. Shapiro IM, Cornblath DR, Sumner AJ, et al. Neurophysiological and neuropsychological functions in mercury-exposed dentists. Lancet 1982;8282:1147-1150

16. Albers JW, Cavender GD, Levine SP, Langolf GD. Asymptomatic sensorimotor polyneuropathy in workers exposed to elemental mercury. Neurology 1982;32:1168-1174

17. Langolf GD, Chaffin DB, Henderson R, Whittle HP. Evaluation of workers exposed to elemental mercury using quantitative tests of tremor and neuromuscular functions. Am Ind Hyg Assoc J 1978;39:976-984

18. Langolf GD, Smith PJ, Henderson R, Whittle HP. Measurements of neurological functions in the evaluations of exposure to neurotoxic agents. Ann Occup Hyg 1981;24:293-296

19. Gilliatt RW. Sensory conduction studies in the early recognition of nerve disorders. Muscle Nerve 1978;1:352-359

20. LeQuesne PM. Neurophysiological investigations of subclinical and minimal toxic neuropathies. Muscle Nerve 1978;1:392-395

21. Daube JR. Nerve conduction studies. In: Aminoff MJ, ed. Electrophysiological approaches to neurological diagnosis. Edinburgh: Churchill-Livingstone, 1980:229-264

22. Levine SP, Cavender GD, Langolf GD, Albers JW. Elemental mercury exposure: peripheral neurotoxicity. Br J Ind Med 1982;39:136-139

23. Von Burg R, Rustam $H$. Electrophysiological investigations of methylmercury intoxication in humans. Evaluation of peripheral nerve by conduction velocity and electromyography. Electroencephalogr Clin Neurophysiol 1974;37:381-392

24. Nielsen VK, Wright KC. Toxic polyneuropathies. In: Brown WF, Bolton CF, eds. Clinical electromyography. Boston: Butterworths, 1987:283-303

25. Feldman RG, Hayes MK, Younes R, Aldrich FD. Lead neuropathy in adults and children. Arch Neurol 1977;34:481-488

26. Savolainen $H$. Toxicological mechanisms in acute and chronic nervous system degeneration. Acta Neurol Scand 1982;55(no. 92, suppl):23-35

27. Jacobs L, Gossman MD. Three primitive reflexes in normal adults. Neurology 1980;30:184-188

28. Chang LW, Hartmann HA. Ultrastructural studies of the nervous system after mercury intoxication. Acta Neuropathol (Berl) 1972;20:128-138

29. Feldman RG. Central and peripheral nervous system effects of metals: a survey. Acta Neurol Scand 1982;66(no. 92, suppl): $143-166$

30. Schaumburg HH, Spencer TS. Recognizing neurotoxic disease. Neurology 1987;37:276-278

31. Albin RA, Albers JW, Greenberg HS, et al. Acute sensory neuropathy-neuronopathy in pyridoxine overdose. Neurology 1987;37:1729-1732

32. Calne DB, Eisen A, McGreer E, Spencer P. Alzheimer's disease, Parkinson's disease and motoneurone disease: abiotropic interaction between ageing and environment. Lancet 1986 8515:1067-1070

33. Spencer PS, Nunn PB, Hugon J, et al. Guam amyotrophic lateral sclerosis-parkinsonism-dementia linked to a plant excitant neurotoxin. Science 1987;237:517-522 